\title{
Associations Between TIM1 Polymorphisms and Dilated Cardiomyopathy in a Han Chinese Population
}

\author{
Xiaochuan XIE, ${ }^{1} \mathrm{MD}$, Chunmei LI, ${ }^{1} \mathrm{MD}$, Bin Zhou, ${ }^{2} \mathrm{PhD}$, \\ Xiaohui DAI, ${ }^{1} \mathrm{MD}$, and $\mathrm{Li} \mathrm{RAO},{ }^{1} \mathrm{MD}$
}

\begin{abstract}
SUMMARY
Immune dysfunction is implicated in dilated cardiomyopathy (DCM). Previous studies found that TIMI polymorphisms were associated with immune dysfunction. However, the associations between TIMI polymorphisms and DCM have not been investigated. Therefore, we conducted the present study to evaluate whether TIMI polymorphisms were associated with DCM in the Han Chinese population. A total of 396 DCM patients and 403 healthy controls were enrolled in this case-control study. Two promoter region single nucleotide polymorphisms (SNPs) of TIM1 gene, $-416 \mathrm{G}>\mathrm{C}$ and $-1454 \mathrm{G}>\mathrm{A}$, were genotyped by PCR-RFLP. The associations between two SNPs genotyped and the overall survival (OS) of DCM patients were evaluated with Kaplan-Meier analysis and Cox regression analysis. Plasma TIM-1 levels were further measured by ELISA. We found that the $\mathrm{C}$ allelic frequency of $-416 \mathrm{G}>\mathrm{C}$ and $\mathrm{A}$ allelic frequency of $-1454 \mathrm{G}>\mathrm{A}$ were higher in DCM patients than that in controls $(P<0.001)$. The genotypic frequencies of both SNPs were associated with DCM susceptibility in the codominant, dominant, and overdominant models $(P<0.01)$. They were also associated with the OS of DCM patients in the dominant, recessive, and overdominant models $(P<0.001)$. The CC genotype of $-416 \mathrm{G}>\mathrm{C}$ and $\mathrm{AA}$ genotype of $-1454 \mathrm{G}>\mathrm{A}$ were associated with the worst prognosis $(P<0.001)$. In addition, the plasma TIM-1 levels in DCM patients were higher than that in controls $(259.0 \mathrm{pg} / \mathrm{mL}$ versus $149.8 \mathrm{pg} / \mathrm{mL}, P=0.035)$. The CC genotype of $416 \mathrm{G}>\mathrm{C}$ and AA genotype of $-1454 \mathrm{G}>\mathrm{A}$ were associated with the highest TIM-1 production $(P<$ 0.01). Overall, our findings suggest that TIM1 polymorphisms are associated with DCM susceptibility and prognosis in this Han Chinese population. (Int Heart J 2016; 57: 742-746)
\end{abstract}

Key words: Single nucleotide polymorphisms, Survival analysis, Enzyme-linked immunosorbent assay

$\mathrm{D}$ ilated cardiomyopathy (DCM), characterized by progressive ventricular chamber enlargement and contractional dysfunction in the absence of associated conditions such as hypertension, ischemic heart disease, valvular heart disease, congenital heart disease, and pulmonary heart disease, is the most common type of cardiomyopathy, accounting for approximately $55-60 \%$ of cardiomyopathies with an estimated prevalence of 1 in 2,500 individuals. ${ }^{1)}$ It is the leading non-ischemic cause of congestive heart failure and sudden cardiac death, and is the most frequent indication for cardiac transplantation in adults and children. ${ }^{2)}$

In the last two decades, extensive studies have been conducted to investigate the etiology of DCM. However, the exact cause of the disease is still largely unknown. Recently, immune dysfunction was demonstrated to be involved in the pathogenesis of DCM. Firstly, it was found that T suppressor (Ts) cells are decreased while T helper (Th) cells are increased in DCM patients. ${ }^{3)}$ Secondly, several cardiac-specific antibodies were detected in serum of DCM patients. ${ }^{4-7)}$ And thirdly, immunosuppressive therapy was shown to be associated with sympto- matic and functional improvements of DCM patients in some pilot studies. ${ }^{89)}$ These findings jointly indicate that immune dysfunction is an important pathogenic factor of DCM.

$\mathrm{T}$ cell immunoglobulin domain and mucin domain-1 (TIM-1), the founding member of the TIM family, which is encoded by the TIM1 gene located on chromosome 5q33.2, is a type 1 transmembrane glycoprotein comprised of an immunoglobulin variable domain, a heavily glycoslyated mucin domain, a single transmembrane domain, and a cytoplasmic tail with one tyrosine phosphorylation motif. ${ }^{10)}$ Studies over the past several years have shown that TIM-1 plays a crucial role in regulating immune responses and maintaining immune homeostasis. In addition, accumulating evidence has demonstrated that immune dysfunction caused by certain TIMI polymorphisms is associated with autoimmune diseases, allergic reactions, chronic viral infections, and immunologic rejections. $^{11)}$

Therefore, we hypothesized that certain TIMI polymorphisms, which cause disturbance of the immune system, may contribute to the occurrence and development of DCM in some

From the ${ }^{1}$ Department of Cardiology, West China Hospital and ${ }^{2}$ Laboratory of Molecular Translational Medicine, West China Second University Hospital, Sichuan University, Chengdu, Sichuan, China.

This study was funded by the National Natural Science Foundation of China $(81270289,81300169)$

Address for correspondence: Li Rao, MD, Department of Cardiology, West China Hospital, Sichuan University, No. 37 Guo Xue Xiang, Chengdu 610041, Sichuan, China. E-mail: raoli8866@163.com

Received for publication March 11, 2016. Revised and accepted April 15, 2016.

Released in advance online on J-STAGE November 4, 2016.

All rights reserved by the International Heart Journal Association. 
patients. In the present study, polymerase chain reaction-restriction fragment length polymorphism (PCR-RFLP) analysis and survival analysis were carried out to evaluate the associations of two single nucleotide polymorphisms (SNPs) located in the promoter region of the TIMI gene $(-416 \mathrm{G}>\mathrm{C}$ and $-1454 \mathrm{G}>\mathrm{A}$ ) with DCM susceptibility and prognosis. In addition, enzyme-linked immunosorbent assay (ELISA) was performed to reveal the potential relationship between TIM1 polymorphisms and TIM-1 protein production.

\section{Methods}

Study subjects: In this case-control study, a cohort of 396 DCM patients (mean age, $49.0 \pm 14.1$; male/female, 246/150) was consecutively recruited from the West China Hospital of Sichuan University between June 2002 and September 2014. The diagnosis of DCM was made in accordance with the criteria established by the World Health Organization/International Society and Federation of Cardiology Task Force on the Classification of Cardiomyopathies in 1995 (before 2006) and the scientific Statement on the Definitions and Classification of Cardiomyopathies proposed by the American Heart Association in 2006 (after 2006). ${ }^{1,12)}$ A total of 403 healthy individuals (mean age, $49.5 \pm 13.1$; male/female, 248/155) from a routine physical examination were enrolled as controls. All subjects were of Han Chinese ethnicity living in Sichuan province, which is located in southwest China. Patients with a history of hypertension, ischemic heart disease, valvular heart disease, congenital heart disease, pulmonary heart disease, tachyarrhythmia, pericardial disease, heavy alcohol consumption, acute viral myocarditis, systemic diseases of putative autoimmune origin, skeletal myopathies or nutrition disorders were intentionally excluded. The baseline characteristics of the study population are summarized in Supplemental Table I. The current study was performed with approval from the West China Hospital Ethics Committee and in accordance with the Declaration of Helsinki. Peripheral blood samples were obtained from all subjects after obtaining written informed consent.

Isolation of genomic DNA and genotyping of two SNPs: Genomic DNA was extracted from peripheral blood samples using a DNA isolation kit (Bioteke, Beijing, China) and the procedure was performed according to the manufacturer's protocol. DNA samples were subsequently stored at $-20^{\circ} \mathrm{C}$ for future use. Genotyping of the two TIM1 SNPs, $-416 \mathrm{G}>\mathrm{C}$ and $-1454 \mathrm{G}>\mathrm{A}$, was carried out using PCR-RFLP analysis. The primer pairs, F: 5'-TAACCGCCAAACTGACTCCT-3' and R: 5'-TCACCCTTTTAGCCAGGATG-3', F: 5'-TCTTGAACT CCCGACCTCAG-3' and R: 5'-TTCATGGGGAAGTGGAT GAT-3', were used to amplify the genomic region surrounding $-416 \mathrm{G}>\mathrm{C}$ and $-1454 \mathrm{G}>\mathrm{A}$, respectively. The $\mathrm{PCR}$ reaction was performed in a total volume of $25 \mu \mathrm{L}$ solution, containing 2.5 $\mu \mathrm{L} 10 \times$ PCR buffer, $1.5 \mathrm{mmol} / \mathrm{L} \mathrm{MgCl}_{2}, 0.15 \mathrm{mmol} / \mathrm{L}$ dNTPs, $0.5 \mu \mathrm{mol} / \mathrm{L}$ each primer, $100 \mathrm{ng}$ genomic DNA, and $2 \mathrm{U}$ of Tag DNA polymerase (NEB, Ipswich, MA, USA). The PCR cycling conditions consisted of an initial denaturation step at $94^{\circ} \mathrm{C}$ for 4 minutes, followed by 36 cycles of denaturation at $94^{\circ} \mathrm{C}$ for 30 seconds, annealing at $58^{\circ} \mathrm{C}(-416 \mathrm{G}>\mathrm{C})$ and $60^{\circ} \mathrm{C}$ $(-1454 \mathrm{G}>\mathrm{A})$ for 30 seconds, extension at $72^{\circ} \mathrm{C}$ for 30 seconds, and a final elongation step at $72^{\circ} \mathrm{C}$ for 10 minutes. To avoid contamination, negative controls without genomic DNA were included in each PCR reaction. PCR products were run on $6 \%$ polyacrylamide gels and visualized by means of silver staining to check whether amplification reactions were successful. After ensuring the success of PCR reactions, $3.5 \mu \mathrm{L}$ of PCR products generated were digested with corresponding locusspecific restriction enzymes in a total volume of $10 \mu \mathrm{L}$ solution for 2-3 hours $\left(2 \mathrm{U} \mathrm{Taq}{ }^{\mathrm{I}} \mathrm{I}\right.$ at $65^{\circ} \mathrm{C}$ for $-416 \mathrm{G}>\mathrm{C}, 2 \mathrm{U}$ MspI at $37^{\circ} \mathrm{C}$ for $-1454 \mathrm{G}>\mathrm{A}$ ) (NEB, Ipswich, MA, USA). The digested products were then separated on $6 \%$ polyacrylamide gels and stained with $1.5 \mathrm{~g} / \mathrm{L}$ argent nitrate for genotypic determination. For genotyping of $-416 \mathrm{G}>\mathrm{C}$ polymorphism, a single uncuttable fragment of $167 \mathrm{bp}$ indicated the GG genotype, the heterozygous GC genotype was indicated by 3 fragments of $167 \mathrm{bp}, 141 \mathrm{bp}$ and $26 \mathrm{bp}$, while the CC genotype was indicated by two fragments of $141 \mathrm{bp}$ and $26 \mathrm{bp}$. For genotyping of the $-1454 \mathrm{G}>\mathrm{A}$ polymorphism, a single uncuttable fragment of 148 bp indicated the AA genotype, the heterozygous GA genotype was indicated by 3 fragments of $148 \mathrm{bp}, 78 \mathrm{bp}$, and $70 \mathrm{bp}$, while the GG genotype was indicated by two fragments of 78 bp and $70 \mathrm{bp}$. About $10 \%$ of the samples were randomly selected for direct sequencing to test the accuracy of genotypic determination and the results were $100 \%$ concordant.

Clinical follow-up: A total of 265 patients who provided contact information in their medical records were arranged for regular follow-up at time intervals of 6-12 months. The clinical follow-up was carried out in a blind manner in regard to the patient's genotypes. The endpoint of follow-up was cardiac death or loss of contact.

Enzyme-linked immunosorbent assay: Plasma was obtained from peripheral blood samples after centrifuging at 2,000 rpm for 10 minutes, and was stored at $-80^{\circ} \mathrm{C}$ until further analysis. To measure plasma levels of TIM-1 in DCM patients and healthy controls, a pre-coated human TIM-1 ELISA kit (Raybiotech, Norcross, GA, USA) was used according to the manufacturer's protocol. The minimum detectable TIM-1 level was $2 \mathrm{pg} / \mathrm{mL}$.

Statistical analysis: All data analyses were performed using SPSS 19.0 statistical software for Windows (SPSS Inc, Chicago, IL, USA). Genotypic and allelic frequencies of the two SNPs genotyped were obtained by directed counting. HardyWeinberg equilibrium (HWE) in the control group was evaluated with the chi-square test. The associations between two SNPs genotyped and DCM susceptibility were assessed in the codominant, dominant, recessive, and overdominant models using SNPstats. Odds ratios (ORs) and 95\% confidence intervals (95\%CIs) were utilized to evaluate the effects of any differences in the distribution of genotypes and alleles. KaplanMeier analysis and Cox regression analysis were further performed to test the correlations between two SNPs genotyped and overall survival (OS) of DCM patients. ELISA data were analyzed with the Pearson correlation test and MannWhitney $U$ test. The Kruskal-Wallis test was subsequently carried out to explore the potential associations of two SNPs genotyped with plasma TIM-1 and brain natriuretic peptide (BNP) levels. A raw probability value ( $P$ value) of 0.05 or less was considered as statistically significant, which was further subjected to Bonferroni correction to account for multiple comparisons. The significance threshold was set at 0.025 for a single SNP test since two SNPs were analyzed. 
Table. Distributions of TIMI SNPs Among Cases and Controls and Their Associations With DCM Susceptibility

\begin{tabular}{|c|c|c|c|c|c|c|c|c|c|c|}
\hline \multirow[b]{3}{*}{ Model } & \multirow[b]{3}{*}{ Genotype } & \multicolumn{4}{|c|}{$-416 \mathrm{G}>\mathrm{C}(\mathrm{rs} 9313422)$} & & \multicolumn{4}{|c|}{$-1454 \mathrm{G}>\mathrm{A}(\mathrm{rs} 41297579)$} \\
\hline & & $\begin{array}{c}\text { Cases, } n \\
(\%)\end{array}$ & $\begin{array}{c}\text { Controls, } n \\
(\%)\end{array}$ & OR $(95 \% \mathrm{CI})$ & $P$ & & $\begin{array}{c}\text { Cases, } n \\
(\%)\end{array}$ & $\begin{array}{c}\text { Controls, } n \\
(\%)\end{array}$ & OR $(95 \% \mathrm{CI})$ & $P$ \\
\hline & & & & & & Genotype & & & & \\
\hline \multirow[t]{3}{*}{ Codominant } & GG & $159(40.1 \%)$ & $213(52.9 \%)$ & 1.00 & \multirow[t]{3}{*}{0.0015} & GG & $271(68.4 \%)$ & $318(78.9 \%)$ & 1.00 & \multirow[t]{3}{*}{0.0021} \\
\hline & GC & $194(49 \%)$ & $156(38.7 \%)$ & $1.67(1.23-2.22)$ & & GA & $106(26.8 \%)$ & $76(18.9 \%)$ & $1.64(1.16-2.27)$ & \\
\hline & $\mathrm{CC}$ & $43(10.9 \%)$ & $34(8.4 \%)$ & $1.69(1.03-2.78)$ & & AA & $19(4.8 \%)$ & $9(2.2 \%)$ & $2.50(1.10-5.56)$ & \\
\hline \multirow[t]{2}{*}{ Dominant } & GG & $159(40.1 \%)$ & $213(52.9 \%)$ & 1.00 & \multirow{2}{*}{$<0.001$} & GG & $271(68.4 \%)$ & $318(78.9 \%)$ & 1.00 & \multirow{2}{*}{$<0.001$} \\
\hline & $\mathrm{GC} / \mathrm{CC}$ & $237(59.9 \%)$ & $190(47.1 \%)$ & $1.67(1.27-2.22)$ & & GA/AA & $125(31.6 \%)$ & $85(21.1 \%)$ & $1.72(1.25-2.38)$ & \\
\hline \multirow[t]{2}{*}{ Recessive } & GG/GC & $353(89.1 \%)$ & $369(91.6 \%)$ & 1.00 & \multirow[t]{2}{*}{0.25} & GG/GA & $377(95.2 \%)$ & $394(97.8 \%)$ & 1.00 & \multirow[t]{2}{*}{0.046} \\
\hline & $\mathrm{CC}$ & $43(10.9 \%)$ & $34(8.4 \%)$ & $1.32(0.83-2.13)$ & & AA & $19(4.8 \%)$ & $9(2.2 \%)$ & $2.22(0.99-5.00)$ & \\
\hline \multirow[t]{5}{*}{ Overdominant } & GG/CC & $202(51 \%)$ & $247(61.3 \%)$ & 1.00 & \multirow[t]{3}{*}{0.0034} & GG/AA & $290(73.2 \%)$ & $327(81.1 \%)$ & 1.00 & \multirow[t]{3}{*}{0.0076} \\
\hline & GC & $194(49 \%)$ & $156(38.7 \%)$ & $1.52(1.15-2.00)$ & & GA & $106(26.8 \%)$ & $76(18.9 \%)$ & $1.56(1.12-2.17)$ & \\
\hline & Allele & & & & & Allele & & & & \\
\hline & G & $512(64.6 \%)$ & $582(72.2 \%)$ & 1.00 & \multirow{2}{*}{$<0.001$} & $\mathrm{G}$ & $648(81.8 \%)$ & $712(88.3 \%)$ & 1.00 & \multirow{2}{*}{$<0.001$} \\
\hline & $\mathrm{C}$ & $280(35.4 \%)$ & $224(27.8 \%)$ & $1.43(1.15-1.75)$ & & A & $144(18.2 \%)$ & $94(11.7 \%)$ & $1.67(1.27-2.22)$ & \\
\hline
\end{tabular}

\section{RESUlts}

In the present study, two SNPs located in the promoter region of the TIMI gene, $-416 \mathrm{G}>\mathrm{C}$ and $-1454 \mathrm{G}>\mathrm{A}$, were genotyped in 396 DCM patients and 403 healthy controls. The distributions of the two SNPs were both in accordance with HWE $(P>0.05)$ in the control group, indicating that the genotypic and allelic frequencies of the two SNPs met the expected equilibrium and thus were representative. The associations between the two SNPs genotyped and DCM susceptibility were determined by comparing genotypic and allelic frequencies in DCM patients and healthy controls. As shown in the Table, statistically significant differences were found for both SNPs. The genotypic frequency of $-416 \mathrm{G}>\mathrm{C}$ was associated with DCM susceptibility in the codominant model [OR $=1.67$ (1.69), 95\%CI 1.23-2.22 (1.03-2.78), $P=0.0015]$, the dominant model $(\mathrm{OR}=1.67,95 \% \mathrm{CI} 1.27-2.22, P<0.001)$, and the overdominant model $(\mathrm{OR}=1.52,95 \%$ CI $1.15-2.00, P=$ $0.0034)$. The $\mathrm{C}$ allelic frequency in DCM patients and healthy controls was $35.4 \%$ and $27.8 \%$, respectively, which was significantly higher in DCM patients than that in healthy controls $(\mathrm{OR}=1.43,95 \% \mathrm{CI} 1.15-1.75, P<0.001)$. Similarly, the genotypic frequency of $-1454 \mathrm{G}>\mathrm{A}$ was also associated with DCM susceptibility in the codominant model [OR $=1.64(2.50)$, 95\%CI 1.16-2.27 (1.10-5.56), $P=0.0021]$, the dominant model $(\mathrm{OR}=1.72,95 \% \mathrm{CI} 1.25-2.38, P<0.001)$, and the overdominant model $(\mathrm{OR}=1.56,95 \% \mathrm{CI} 1.12-2.17, P=0.0076)$. The A allelic frequency in DCM patients and healthy controls was $18.2 \%$ and $11.7 \%$, respectively, which was also significantly higher in DCM patients than that in healthy controls $(\mathrm{OR}=1.67,95 \%$ CI $1.27-2.22, P<0.001)$.

The correlations between the two SNPs genotyped and prognosis of DCM patients were subsequently assessed in survival analysis. The 265 contactable DCM patients (mean age, $48.7 \pm 14.2$; male/female, 175/90) were screened for a mean period of $69.0 \pm 20.4$ months. During follow-up, all patients received continuous medication treatment and none underwent heart transplantation. At the end of the present study, 183 patients $(69.1 \%)$ had suffered cardiac death. Kaplan-Meier analy- sis revealed a significant association between both SNPs and the prognosis of DCM patients. Hazard ratios (HRs) and 95\%CIs were further evaluated in the Cox regression analysis with adjustment for age, sex, NYHA (New York Heart Association functional class), LVEDD (left ventricular end-diastolic diameter), LVEF (left ventricular ejection fraction), and BNP level. As shown in Supplemental Table II, the univariate survival analysis demonstrated that genotypic frequency of $-416 \mathrm{G}>\mathrm{C}$ was significantly associated with OS of DCM patients in the dominant model $(\mathrm{HR}=3.26,95 \% \mathrm{CI} 2.37-4.49, P$ $<0.001)$, the recessive model $(\mathrm{HR}=3.98,95 \% \mathrm{CI} 2.49-6.37, P$ $<0.001)$, and the overdominant model $(\mathrm{HR}=2.16,95 \% \mathrm{CI}$ $1.59-2.94, P<0.001)$. Patients with GG genotype showed the longest survival time, GC genotype was associated with middle-term survival, and CC genotype carriers presented the worst prognosis (Figure A, $P<0.001$ ). Similarly, genotypic frequency of $-1454 \mathrm{G}>\mathrm{A}$ was also associated with OS of DCM patients in the dominant model $(\mathrm{HR}=3.61,95 \% \mathrm{CI} 2.61-5.00$, $P<0.001)$, the recessive model $(\mathrm{HR}=7.58$, 95\%CI 3.86$14.93, P<0.001)$, and the overdominant model $(\mathrm{HR}=2.84$, 95\%CI 2.03-3.97, $P<0.001)$. Patients with GG genotype showed the longest survival time, GA genotype was associated with middle-term survival, and AA genotype carriers presented the worst prognosis (Figure B, $P<0.001$ ). These associations remained significant in the multivariable survival analysis after Cox regression adjusting for potential confounding factors $(P$ $<0.001)$.

Plasma TIM-1 levels were further determined in 30 DCM patients and 38 healthy controls. As shown in Supplemental Figure A, the plasma TIM-1 levels in DCM patients were significantly higher than that in healthy controls $(259.0 \mathrm{pg} / \mathrm{mL}$ versus $149.8 \mathrm{pg} / \mathrm{mL}, P=0.035$ ). We further accessed the relationship between different genotypes of the two SNPs and plasma levels of TIM-1. We found that the GG genotype of $-416 \mathrm{G}>\mathrm{C}$ resulted in significantly lower TIM-1 production in comparison with the GC or CC genotypes $(P=0.007)$ (Supplemental Figure B). Similarly, the GG genotype of -1454G $>$ A was also associated with significantly lower TIM-1 production than the GA or AA genotypes $(P=0.017)$ (Supplemental Fig- 

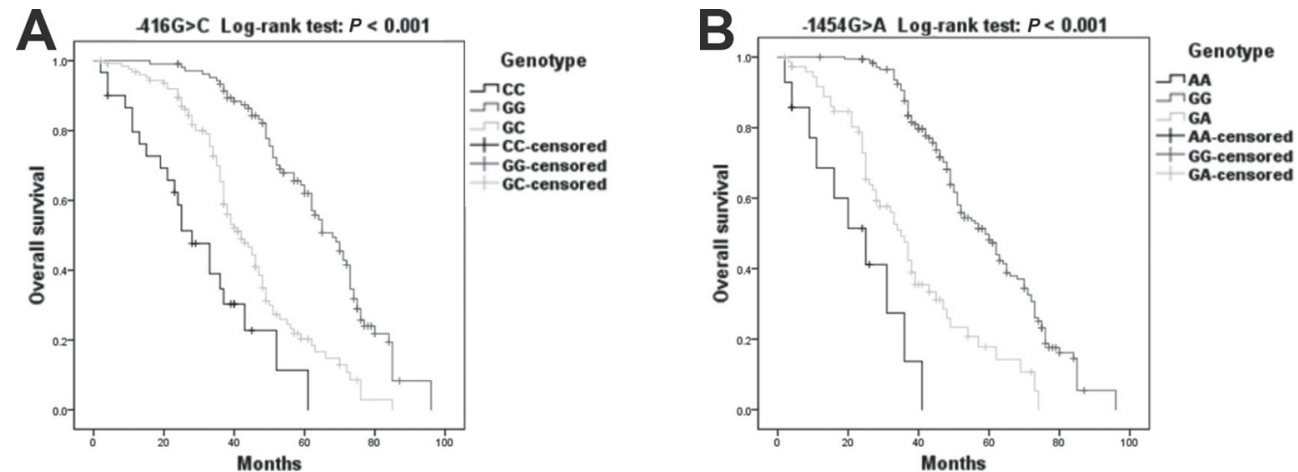

Figure. Kaplan-Meier curves of DCM patients carrying different genotypes of TIM1 SNPs. A: TIM1 -416G>C SNP. B: TIM1 -1454G>A SNP.

ure C). However, we detected no significant associations between BNP levels and TIM-1 -416G $>\mathrm{C}(P=0.208)$ or $-1454 \mathrm{G}>\mathrm{A}(P=0.141)$ SNPs.

\section{Discussion}

DCM is a complex disorder with extremely high fatality rate, despite rapid advancements in pharmacologic therapy and surgical treatment over the past 20 years, there is little improvement in its prognosis. According to several recent investigations, DCM is still one of the major causes of morbidity and mortality, especially in youngsters and those in their productive years of life. ${ }^{13,14)}$ Thus, a better understanding of the pathogenesis of DCM is essential to further improve its survival. Human TIM gene family, which contains TIM1, TIM3 and TIM4, is located on chromosome 5q23-35, a region that has been repeatedly linked with immune dysfunction, which may subsequently lead to autoimmune diseases, allergic diseases, chronic viral infections, immune rejections, and tumors. ${ }^{10,11,15}$ The TIMI gene, also known as hepatitis A virus cellular receptor 1 (HAVCRl) or kidney injury molecule 1 (KIMI), is a vital causative agent of immunological injuries and inflammatory disorders. Previous studies have demonstrated that transient over-expression of TIM1 or cross-linking TIM-1 with agonistic antibodies, in conjunction with $\mathrm{T}$ cell receptor (TCR) signal complex and CD28 stimulation, enhances T cell proliferation and cytokine production, which associates with various inflammatory disorders. ${ }^{16)}$ Furthermore, Kobayashi, et $a l^{17)}$ and Kim, et $a l^{18)}$ reported that TIM-1 serves as a receptor for PtdSer, a signal of programmed cell death. The recognition of ptdSer by TIM-1 is essential for natural killer T (NKT) cells and macrophages to identify and respond to apoptotic cells. Although apoptosis is classically considered as a "silent death", it has become evident recently that excessive apoptosis can be highly immunogenic, with the ability to elicit strong immunologic responses and heavy inflammatory injuries. ${ }^{19)}$ Moreover, certain TIM1 polymorphisms were demonstrated to be related to immunological disorders such as asthma, ${ }^{20,21)}$ allergic rhinitis, ${ }^{22)}$ atopic dermatitis, ${ }^{23)}$ rheumatoid arthritis, ${ }^{24,25)}$ myasthenia gravis, ${ }^{26)}$ HAV infection and its associated acute liver failure, ${ }^{27)}$ persist hepatitis $\mathrm{C}$ virus (HCV) infection, ${ }^{28)}$ and filovirus infection $^{29)}$ in different populations. Hence, we surmised that the TIM1 gene may be a potential candidate marker for DCM susceptibility and prognosis.
In the present study, we investigated the associations between two SNPs located in the promoter region of the TIMI gene and DCM in a Han Chinese population. Although promoter region polymorphisms cannot change the coding sequence of a specific gene, they are found to affect initiation and promotion of gene transcription, and thus may be pathogenic. Previous studies showed that TIM1 $-416 \mathrm{G}>\mathrm{C}$ SNP was associated with susceptibility to asthma and allergic rhinitis, ${ }^{20-22)}$ and TIM1 -1454G $>$ A SNP was associated with susceptibility to allergic rhinitis and rheumatoid arthritis. ${ }^{22,24,25)}$ In addition, luciferase reporter assay and allele-specific transcript quantification analysis demonstrated that base substitution in both sites can lead to an increased transcriptional activity of the TIMI gene. ${ }^{30,31)}$ To the best of our knowledge, the current research is the first attempt to ascertain whether certain TIMI polymorphisms are associated with DCM susceptibility and prognosis. We found that the genotypic frequencies of the two SNPs genotyped were associated with DCM susceptibility in the codominant, dominant, and overdominant models. They were also associated with OS of DCM patients in the dominant, recessive, and overdominant models. Furthermore, the $\mathrm{C}$ allele of $-416 \mathrm{G}>\mathrm{C}$ as well as the A allele of $-1454 \mathrm{G}>\mathrm{A}$ were associated with an increased susceptibility to DCM, and the $\mathrm{CC}$ genotype of $-416 \mathrm{G}>\mathrm{C}$ as well as the AA genotype of $-1454 \mathrm{G}>\mathrm{A}$ were associated with the worst prognosis of DCM patients. Moreover, plasma levels of TIM-1 were elevated in DCM patients. Also, the GG genotype of $-416 \mathrm{G}>\mathrm{C}$ showed lower plasma TIM-1 levels than the GC or CC genotypes. Similarly, the GG genotype of $-1454 \mathrm{G}>\mathrm{A}$ also demonstrated lower plasma TIM-1 levels compared with the GA or AA genotypes. The C allele of $-416 \mathrm{G}>\mathrm{C}$ and A allele of $-1454 \mathrm{G}>\mathrm{A}$ were associated with the highest TIM-1 production.

Overall, based on our findings, $-416 \mathrm{G}>\mathrm{C}$ and $-1454 \mathrm{G}>\mathrm{A}$ SNPs of the TIMI gene may predispose to the pathogenesis of DCM by up-regulating TIM-1 protein production. However, future studies are needed to better elucidate the underlying mechanisms of the associations observed between the two SNPs genotyped and DCM since the sample size of the present ELISA assessment was relatively small, which precluded us from drawing definite conclusions.

Conclusion: In conclusion, the present study suggests that TIMI $-416 \mathrm{G}>\mathrm{C}$ and $-1454 \mathrm{G}>\mathrm{A}$ SNPs are associated with DCM susceptibility and prognosis in this Han Chinese population. However, further studies with larger sample sizes are warranted to confirm the significance of these associations and 
better clarify the mechanisms involved. Finally, given its highly polymorphic characteristic, future investigations are needed to explore the potential roles of other TIMI polymorphisms in the pathogenesis of DCM.

\section{Disclosure}

The authors report no conflicts of interest regarding the content herein.

\section{REFERENCES}

1. Maron BJ, Towbin JA, Thiene G, et al. Contemporary definitions and classification of the cardiomyopathies: an American Heart Association Scientific Statement from the Council on Clinical Cardiology, Heart Failure and Transplantation Committee; Quality of Care and Outcomes Research and Functional Genomics and Translational Biology Interdisciplinary Working Groups; and Council on Epidemiology and Prevention. Circulation 2006; 113: 1807-16.

2. Lakdawala NK, Winterfield JR, Funke BH. Dilated cardiomyopathy. Circ Arrhythm Electrophysiol 2013; 6: 228-37. (Review)

3. Yoshikawa T, Baba A, Nagatomo Y. Autoimmune mechanisms underlying dilated cardiomyopathy. Circ J 2009; 73: 602-7. (Review)

4. Baba A, Yoshikawa T, Ogawa S. Autoantibodies produced against sarcolemmal Na-K-ATPase: possible upstream targets of arrhythmias and sudden death in patients with dilated cardiomyopathy. J Am Coll Cardiol 2002; 40: 1153-9.

5. Störk S, Boivin V, Horf R, et al. Stimulating autoantibodies directed against the cardiac beta1-adrenergic receptor predict increased mortality in idiopathic cardiomyopathy. Am Heart J 2006; 152 697-704.

6. Baba A, Yoshikawa T, Fukuda Y, et al. Autoantibodies against M2muscarinic acetylcholine receptors: new upstream targets in atrial fibrillation in patients with dilated cardiomyopathy. Eur Heart J 2004; 25 : 1108-15.

7. Lauer B, Schannwell M, Kühl U, Strauer BE, Schultheiss HP. Anti-myosin autoantibodies are associated with deterioration of systolic and diastolic left ventricular function in patients with chronic myocarditis. J Am Coll Cardiol 2000; 35: 11-8.

8. Mobini R, Maschke H, Waagstein F. New insights into the pathogenesis of dilated cardiomyopathy: possible underlying autoimmune mechanisms and therapy. Autoimmun Rev 2004; 3: 277-84. (Review)

9. Frustaci A, Chimenti C, Calabrese F, Pieroni M, Thiene G, Maseri A. Immunosuppressive therapy for active lymphocytic myocarditis: virological and immunologic profile of responders versus nonresponders. Circulation 2003; 107: 857-63.

10. Freeman GJ, Casasnovas JM, Umetsu DT, DeKruyff RH. TIM genes: a family of cell surface phosphatidylserine receptors that regulate innate and adaptive immunity. Immunol Rev 2010; 235 : 172-89. (Review)

11. Su EW, Lin JY, Kane LP. TIM-1 and TIM-3 proteins in immune regulation. Cytokine 2008; 44: 9-13. (Review)

12. Richardson P, McKenna W, Bristow M, et al. Report of the 1995 World Health Organization/International Society and Federation of Cardiology Task Force on the Definition and Classification of cardiomyopathies. Circulation 1996; 93: 841-2.

13. Lee CS, Chien CV, Bidwell JT, et al. Comorbidity profiles and inpatient outcomes during hospitalization for heart failure: an analysis of the U.S. Nationwide inpatient sample. BMC Cardiovasc Disord 2014; 14: 73 .

14. Shamszad P, Hall M, Rossano JW, et al. Characteristics and outcomes of heart failure-related intensive care unit admissions in children with cardiomyopathy. J Card Fail 2013; 19: 672-7.
15. Zhang Y, Ji H, Shen X, et al. Targeting TIM-1 on CD4 T Cells depresses macrophage activation and overcomes ischemia-reperfusion injury in mouse orthotopic liver transplantation. Am J Transplant 2013; 13: 56-66.

16. Umetsu SE, Lee WL, McIntire JJ, et al. TIM-1 induces T cell activation and inhibits the development of peripheral tolerance. Nat Immunol 2005; 6: 447-54.

17. Kobayashi N, Karisola P, Peña-Cruz V, et al. TIM-1 and TIM-4 glycoproteins bind phosphatidylserine and mediate uptake of apoptotic cells. Immunity 2007; 27: 927-40.

18. Kim HY, Chang YJ, Chuang YT, et al. T-cell immunoglobulin and mucin domain 1 deficiency eliminates airway hyperreactivity triggered by the recognition of airway cell death. J Allergy Clin Immunol 2013; 132: 414-25.

19. Griffith TS and Ferguson TA. Cell death in the maintenance and abrogation of tolerance: the five Ws of dying cells. Immunity 2011; 35: 456-66. (Review)

20. Shirzade H, Meshkat R, Ganjalikhani-Hakemi M, et al. Association analysis of $-416 \mathrm{G}>\mathrm{C}$ polymorphism of T-cell immunoglobulin and mucin domain-1 gene with asthma in Iran. Int J Immunogenet 2015; 42: 265-9.

21. Mete F, Ozkaya E, Aras S, Koksal V, Etlik O, Baris I. Association between gene polymorphisms in TIM, TSLP, IL18R1 and childhood asthma in Turkish population. Int J Clin Exp Med 2014; 7: 1071-7.

22. Mou Z, Shi J, Tan Y, et al. Association between TIM-1 gene polymorphisms and allergic rhinitis in a Han Chinese population. J Investig Allergol Clin Immunol 2010; 20: 3-8.

23. Page NS, Jones G, Stewart GJ. Genetic association studies between the $\mathrm{T}$ cell immunoglobulin mucin (TIM) gene locus and childhood atopic dermatitis. Int Arch Allergy Immunol 2006; 141: 331-6.

24. Mosaad YM, El-bassiony SR, El-Ghaweet AE, Elhindawy MM, El-Deek BS, Sultan WA. TIM-1 rs41297579 G>A (-1454) and TIM-4 rs7700944 gene polymorphisms as possible risk factor for rheumatoid arthritis: relation to activity and severity. Int J Immunogenet 2015; 42: 254-64.

25. Xu JR, Yang Y, Liu XM, Sun JY, Wang YJ. Polymorphisms of the TIM-1 gene are associated with rheumatoid arthritis in the Chinese Hui minority ethnic population. Genet Mol Res 2012; 11: 619.

26. Zheng K, Xu G, Lu X, Zhang J, Zhang P. Expression and polymorphisms of $\mathrm{T}$ cell immunoglobulin domain and mucin domain protein-1 in thymoma with or without myasthenia gravis. Oncol Lett 2014; 8: 317-22.

27. Kim HY, Eyheramonho MB, Pichavant M, et al. A polymorphism in TIM1 is associated with susceptibility to severe hepatitis A virus infection in humans. J Clin Invest 2011; 121: 1111-8.

28. Wojcik G, Latanich R, Mosbruger T, et al. Variants in HAVCR1 gene region contribute to hepatitis $C$ persistence in African Americans. J Infect Dis 2014; 209: 355-9.

29. Kuroda M, Fujikura D, Noyori O, et al. A polymorphism of the TIM-1 IgV domain: implications for the susceptibility to filovirus infection. Biochem Biophys Res Comun 2014; 455: 223-8.

30. Liu Q, Shang L, Li J, et al. A functional polymorphism in the TIM-1 gene is associated with asthma in a Chinese Han population. Int Arch Allergy Immunol 2007; 144: 197-202.

31. Nuchnoi P, Ohashi J, Kimura R, et al. Significant association between TIM1 promoter polymorphisms and protection against cerebral malaria in Thailand. Ann Hum Genet 2008; 72: 327-36.

\section{SupPlemental Files}

Supplemental Tables I, II

Supplemental Figure

Please see supplemental files;

https://www.jstage.jst.co.jp/article/ihj/57/6/57_16-119/_article/supplement 